\title{
SECAGEM A VÁCUO DE SPIRULINA SP. LEB 18: ANÁLISE DAS CARACTERÍSTICAS DOS COMPOSTOS BIOATIVOS DO PRODUTO DESIDRATADO
}

\author{
A. A. COMITRE ${ }^{1}$, L. B. VAZ ${ }^{1}$, L. A. SILVA ${ }^{1}$, A. P. Q. LARROSA ${ }^{1}$ e L. A. de A. PINTO ${ }^{1}$ \\ ${ }^{1}$ Universidade Federal de Rio Grande, Escola de Química e Alimentos \\ E-mail para contato: dqmpinto@furg.br
}

\begin{abstract}
RESUMO - As microalgas têm sido amplamente cultivadas e estudadas devido à sua rica composição química para fins alimentícios, farmacêuticos, biocombustíveis, biofilmes, dentre outras aplicações. A secagem é uma operação unitária que tem sido empregada para conservação dos nutrientes da biomassa, sendo a secagem a vácuo pouco explorada. Diante disso, este trabalho teve como objetivo de avaliar a secagem a vácuo da microalga Spirulina LEB-18 em relação ao conteúdo de ficocianina, compostos fenólicos e atividade antioxidante. A microalga foi cedida pelo Laboratório de Engenharia Bioquímica da FURG, sendo cultivada em fotobiorreatores abertos, utilizando meio de cultivo Zarrouk. A biomassa era prensada atingindo uma concentração de sólidos de $18 \%(\mathrm{~g} / \mathrm{g})$. Os experimentos foram realizados em uma estufa a vácuo à pressão de $100 \mathrm{mmHg}$ $(13,3 \mathrm{kPa})$ nas temperaturas 40,50 e $60^{\circ} \mathrm{C}$. Os resultados mostraram que com o aumento da temperatura houve uma redução de $26 \%$ a $70 \%$ no conteúdo de ficocianina, sendo que na menor temperatura $\left(40^{\circ} \mathrm{C}\right)$ obteve uma maior preservação da ficobiliproteína. Em relação às demais respostas, compostos fenólicos e atividade antioxidante, os resultados foram similares à amostra in natura independente da temperatura utilizada.
\end{abstract}

\section{INTRODUÇÃO}

As microalgas são uma das fontes mais promissoras para desenvolvimento de novos produtos alimentares e alimentos funcionais, sendo utilizadas para melhorar o valor nutritivo dos alimentos, devido à sua composição química equilibrada. Há um grande número de espécies de microalgas sendo cultivadas, sendo as cianobactérias as mais estudadas e utilizadas (Batista et al., 2013).

A Spirulina é uma microalga fotossintética, filamentosa, espiralada, multicelular e de coloração azul-esverdeada que tem sido produzida em ampla escala (Koru, 2012). Possui elevado conteúdo de proteína (50-60\%), ácidos graxos essenciais, vitaminas e minerais, sendo utilizada para fins farmacêuticos, suplementos alimentares, biocombustíveis, dentre outros. Na região sul do Brasil, situado na Lagoa da Mangueira, há uma planta piloto que possui uma capacidade de produzir $50 \mathrm{~kg}$ por mês de biomassa para enriquecer alimentos, nos quais são distribuídos como snacks para crianças na região (Morais et al., 2010). Além da elevada concentração protéica, a Spirulina contém compostos antioxidantes que possuem efeitos terapêuticos e anti-cancerígenos, assim como pigmentos de interesse como clorofila e as 
ficobiliproteínas. A principal ficobiliproteína é a ficocianina, pigmento verde-azulado que tem sido empregado como corantes naturais em cosméticos e alimentos. Porém, a sua aplicação é frequentemente limitada pela sua instabilidade à umidade, luz e temperatura devido à degradação da fração protéica (Chaiklahan et al., 2012).

No entanto, para aumentar a vida útil da biomassa, é necessário empregar um método de conservação, sendo a secagem uma das operações mais utilizadas. Além de reduzir a atividade de água até um nível em que o crescimento microbiano e reações de deterioração são minimizados, a secagem reduz custos de transporte, embalagem e de armazenamento (VegaGálvez et al., 2011). A secagem de microalgas tem sido realizada em secadores de bandeja (Oliveira et al., 2010), spray dryer, freeze-dryer (Ryckebosch et al., 2011), leito de jorro (Oliveira et al., 2008) e secagem solar. Estudos utilizando secagem a vácuo em microalgas ainda não foram reportados na literatura.

A secagem a vácuo é um processo em que a conteúdo de umidade do material é removido através da pressão abaixo da atmosfera, apresentando diversas vantagens frente aos secadores convencionais, como por exemplo, a oxidação do produto é reduzida pela ausência de oxigênio. Além disso, a secagem a vácuo é um processo alternativo à liofilização por consumir menos energia, tornando-se uma técnica mais barata (Reis, 2011). Em vista, do pouco conhecimento sobre a influência da secagem a vácuo nas microalgas, este trabalho teve como objetivo de avaliar a secagem a vácuo da Spirulina LEB-18 nas suas características funcionais e físico-químicas, tais como: ficocianina, compostos fenólicos e atividade antioxidante.

\section{MATERIAIS E MÉTODOS}

\subsection{Matéria-prima}

Para a realização deste trabalho foi utilizada a microalga Spirulina Leb-18, a qual foi cedida pelo laboratório de Engenharia Bioquímica (LEB/FURG/RS). A microalga foi cultivada em fotobiorreatores abertos em condições não controladas, utilizando meio de cultivo Zarrouk, preparado com água da Lagoa Mangueira para manutenção do inóculo e obtenção da biomassa. A biomassa foi filtrada (200 mesh) e prensada a $1 \mathrm{ton} / \mathrm{cm}^{2}$, obtendo uma concentração de sólidos de $18 \%(\mathrm{~g} / \mathrm{g})$.

\subsection{Experimentos de secagem}

A secagem da microalga foi realizada num secador a vácuo sob pressão reduzida de $100 \mathrm{~mm}$ de $\mathrm{Hg}(13,3 \mathrm{kPa})$ nas temperaturas 40,50 e $60^{\circ} \mathrm{C}$. As condições de vácuo dentro da câmara foram mantidas por uma bomba de vácuo e monitoradas através de um manômetro. $\mathrm{O}$ sistema de aquecimento foi constituído por uma placa de aço inoxidável, com dimensões de $30 \mathrm{~cm}$ de largura e $26,5 \mathrm{~cm}$ de comprimento, aquecida por uma resistência elétrica de $443 \mathrm{~W}$ ligada a um regulador automático de temperatura. A Spirulina foi colocada em uma bandeja de dimensões $(14,5 \mathrm{~cm} \times 16 \mathrm{~cm})$ no formato de pellets cilíndrico de $4 \mathrm{~mm}$ de diâmetro. A medida da massa das amostras durante a secagem foi determinada numa balança semianalítica a cada $1 \mathrm{~h}$, tendo um intervalo de $1 \mathrm{~min}$, a cada pesagem. O término da secagem da Spirulina foi estabelecida até atingir umidade em torno de $0,10 \mathrm{~g}$ de água/g sólido seco. A 


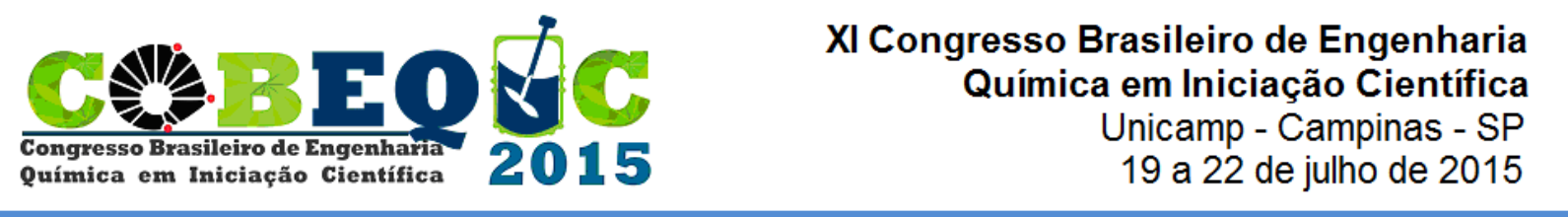

amostra seca foi submetida à redução de tamanho utilizando um moinho de facas para uniformizar o tamanho de partícula.

\subsection{Metodologia analítica}

Ficocianina: foi analisada utilizando o método de Moraes et al. (2010). O método utiliza uma proporção de $0,16 \mathrm{~g}_{\text {biomassa seca }} / \mathrm{mL}_{\text {solvente, }}$ utilizando água destilada como solvente extrator. As amostras (in natura e seca) foram agitadas a $100 \mathrm{rpm}$ durante $4 \mathrm{~h}$ em shaker, sendo centrifugadas a $3500 \mathrm{rpm}$ por $20 \mathrm{~min}$ e filtradas em papel filtro. Retirou-se uma alíquota de $1 \mathrm{~mL}$ e diluída em $25 \mathrm{~mL}$ para leitura no espectrofotômetro nos comprimentos de onda de 620 e $652 \mathrm{~nm}$. A ficocianina foi determinada de acordo com a Equação 1 segundo Bennet e Bogorad (1973), sendo os valores convertidos para mg/g.

$$
F_{C}=\frac{a b s_{620}-0,474\left(a b s_{652}\right)}{5,34}
$$

Compostos Fenólicos: foram determinados de acordo com a metodologia de Assis et al. (2014), utilizando uma extração com álcool metílico e precipitação dos compostos nãofenólicos com hidróxido de bário $0,1 \mathrm{M}$ e sulfato de zinco $5 \%(\mathrm{p} / \mathrm{v})$. A quantificação foi realizada empregando uma curva padrão de ácido gálico utilizando o reagente FolinCiocalteau e a leitura no espectrofotômetro em $750 \mathrm{~nm}$. Os resultados foram expressos por mg de compostos fenólicos totais em equivalente de ácido gálico (EAG) por grama de amostra seca.

Atividade antioxidante: foi determinada pelo método da capacidade de sequestrar o radical estável 1,1-difenil-2-picrihidrazil (DPPH), segundo Brand-Williams et al.,(1995) com algumas modificações. Foi utilizada $500 \mu \mathrm{L}$ de amostra em contato com 3,5 mL de DPPH $0,06 \mathrm{mM}$ em solução metanólica. Após a incubação durante $60 \mathrm{~min}$ em temperatura ambiente e no escuro, foram analisadas as leituras na absorbância de $515 \mathrm{~nm}$. Os resultados foram expressos em \% de inibição de DPPH de acordo com a equação 2.

$$
\% A A=\frac{a b s_{\text {branco }}-a b s_{\text {amostra }}}{a b s_{\text {branco }}}
$$

\subsection{Metodologia estatística}

Os resultados foram tratados estatisticamente pelo do teste de Tukey a um intervalo de $95 \%$ de confiança $(\mathrm{p}<0,05)$. Os experimentos foram realizados em réplica e as análises em triplicata.

\section{RESULTADOS E DISCUSSÃO}

Os resultados dos experimentos na secagem a vácuo foram comparados com a amostra in natura conforme mostra a Tabela 1. 
Tabela 1 - Conteúdo de ficocianina, compostos fenólicos e atividade antioxidante das amostras secas e in natura

\begin{tabular}{ccccc}
\hline Amostra & $\begin{array}{c}\text { Tempo } \\
(\mathrm{h})\end{array}$ & $\begin{array}{c}\text { Ficocianina } \\
(\mathrm{mg} / \mathrm{g})^{*}\end{array}$ & $\begin{array}{c}\text { Fenóis } \\
\left(\mathrm{mg}_{\text {EAG }} / \mathrm{g}_{\mathrm{amostra}}\right)^{*}\end{array}$ & $\begin{array}{c}\text { Atividade } \\
\text { antioxidante } \\
(\% \mathrm{DPPH})^{*}\end{array}$ \\
\hline $40^{\circ} \mathrm{C}$ & $11 \pm 1$ & $31,0 \pm 0,2^{\mathrm{a}}$ & $385,1 \pm 12,9^{\mathrm{a}}$ & $46,3 \pm 1,4^{\mathrm{a}}$ \\
$50^{\circ} \mathrm{C}$ & $8 \pm 1$ & $14,0 \pm 0,6^{\mathrm{b}}$ & $472,2 \pm 1,73^{\mathrm{b}}$ & $54,6 \pm 1,5^{\mathrm{b}, \mathrm{c}}$ \\
$60^{\circ} \mathrm{C}$ & $7 \pm 1$ & $11,9 \pm 0,1^{\mathrm{c}}$ & $485,1 \pm 2,42^{\mathrm{b}}$ & $64,3 \pm 5,3^{\mathrm{c}}$ \\
$\begin{array}{c}\text { In } \\
\text { natura }\end{array}$ & - & $42,1 \pm 0,1^{\mathrm{d}}$ & $326,4 \pm 2,71^{\mathrm{c}}$ & $47,9 \pm 1,2^{\mathrm{a}, \mathrm{b}}$ \\
\hline
\end{tabular}

*Média \pm desvio padrão. Letras diferentes na mesma coluna apresentam diferença significativa ao nível de $5 \%$ de significância ( $\mathrm{p}<0,05$ ).

Os resultados apresentados na Tabela 1 mostram que a ficocianina apresentou diferença significativa entre as amostras secas e in natura ao nível de 5\% de significância $(\mathrm{p}<0,5)$. Além disso, foi verificada uma redução da ficocianina com o aumento da temperatura, sendo que na temperatura de $40^{\circ} \mathrm{C}$ houve menor degradação do pigmento fotossintético presente na Spirulina, o qual representou 26\% de perda. Apesar de que nessa condição experimental obteve um maior tempo de secagem, as maiores temperaturas exerceram maior efeito na sua degradação. Como a ficocianina é uma ficobiliproteína, ou seja, constituída por uma fração proteica, o aumento da temperatura fez com que esta proteína presente nos ficobilissomos sofresse uma degradação térmica. Estudos têm relatado que a estabilidade da ficocianina é influenciada por diversos fatores, como $\mathrm{pH}$, temperatura e concentração protéica (Chaiklahan et al., 2012). Oliveira et al. (2010) estudou a secagem em bandeja da Spirulina, mostrando que houve uma perda de $37 \%$ no conteúdo de ficocianina na temperatura de $55^{\circ} \mathrm{C}$ durante $210 \mathrm{~min}$.

Em relação aos compostos fenólicos, as amostras obtidas pela secagem também apresentaram diferença significativa em relação à amostra in natura ao nível de $5 \%$ de significância $(p<0,05)$, sendo que nas temperaturas de 50 e $60^{\circ} \mathrm{C}$ não apresentou diferença significativa entre elas. Além disso, observa-se na Tabela 1, que os compostos fenólicos aumentaram em torno de $18 \%$ a $48 \%$ em relação à biomassa in natura. Este comportamento pode ser explicado pela aplicação do vácuo, causando uma expansão do ar, o que pode ter liberado maior quantidade de compostos bioativos nas células da biomassa. Já em relação à atividade antioxidante dos extratos metanólicos, verificou-se que a maior temperatura apresentou maior capacidade de sequestrar o radical livre DPPH em relação à amostra in natura. Segundo Orikasa et al. (2014), a secagem a vácuo de kiwi também mostrou um aumento da atividade antioxidante. A energia térmica durante a secagem pode ter uma habilidade de quebrar as estruturas moleculares das ligações covalentes mais complexas e liberam alguns compostos antioxidantes. 


\section{CONCLUSÃO}

A partir dos resultados obtidos pode-se dizer que a secagem a vácuo na temperatura de $40^{\circ} \mathrm{C}$ apresentou resultados satisfatórios em relação aos compostos fenólicos, atividade antioxidante e menor degradação da ficocianina, sendo esta a condição mais adequada para secagem de Spirulina.

\section{AGRADECIMENTOS}

Os autores deste trabalho agradecem ao Laboratório de Engenharia Bioquímica (LEB/FURG) pela matéria-prima e à Capes pelo apoio financeiro.

\section{REFERENCIAS}

AOAC, 1995. AOAC. Official Methods of Analysis of the Association of Official Analytical Chemists (1995). Official Analytical Chemists, 16th ed., Washington, DC.

ASSIS, L. M.; MACHADO, A. R.; MOTTA, A. S.; COSTA, J. A. V. SOUZA-SOARES, L. A. Development and characterization of nanovesicles containing phenolic compounds of microalgae Spirulina strain LEB-18 and Chorella pyrenoidosa. Adv. Mat. Phys. Chem., v. 4, p. 6-12, 2014.

BATISTA, A. P.; GOUVEIA, L.; BANDARRA, N. M.; FRANCO, J. M.; RAYMUNDO, A. Comparison of microalgal biomass profiles as novel functional ingredients for food products. Algal Research, v. 2 , p. 164-173, 2013.

BENNETT, A.; BOGORAD, L. Complementary chromatic adaptation in a filamentous bluegreen alga. J. Cell Biol,. v. 58, p. 419-435, 1973.

BRAND-WILLIAMS, W.; CUVELIER, M. E.; BERSET C. Use of free radical method to evaluate antioxidant activity. LWT-Food Sci. Technol., v. 28, p. 25-30, 1995.

CHAIKLAHAN, R.; CHIRASUWAN, N.; BUNNAG, B. Stability ofphycocyanin extracted from Spirulina sp.: influence of temperature, $\mathrm{pH}$ and preservatives. Process Biochem. v. 47, p. 659-664, 2012.

KORU, E. Earth Food Spirulina (Arthrospira): production and quality standarts. Food Additive, Prof. Yehia El-Samragy (Ed.), 2012.

MORAES, C. C.; BURKERT, J. F. M.; KALIL, S. J. C-phycocyanin extraction process for large-scale use. J. Food Biochem., v. 34, p. 133-148, 2010.

OLIVEIRA, E. G.; ROSA, G. S.; MORAES, M. A.; PINTO, L. A. A Phycocyanin content of Spirulina platensis dried in spouted bed and thin layer. J. Food Process Eng., v. 31, p. 34-50, 2008. 
OLIVEIRA, E. G.; DUARTE, J. H.; MORAES, K.; CREXI, V. T.; PINTO, L. A. A. Optimisation of Spirulina platensis convective drying: evaluation of phycocyanin loss and lipid oxidation. Int. J. Food Sci. Tech., v. 45, p. 1572-1578, 2010.

ORIKASA, T.; KOIDE, S.; OKAMOTO, S.; IMAIZUMI, T.; MURAMATSU, Y.; TAKEDA, J. I.; SHIINA, T.; TAGAWA, A. Impacts of hot air and vacum drying on the quality atributes of kiwifruit slices. J. Food Eng., v. 125, p. 51-58, 2014.

REIS, R. F. Secagem a vácuo de yacon: influência das condições de processo sobre parâmetros de qualidade e cinética de secagem. Tese de doutorado de Engenharia de Alimentos, Universidade Federal do Paraná, 62 f., 2011.

RYCKEBOSCH, E.; MUYLAERT, K.; EECKHOUT, M.; RUYSSEN, T.; FOUBERT, I. Influence of drying and storage on lipid and carotenoid stability of the microalga Phaeodactylum tricornutum. J. Agric. Food Chem., v.59, p. 11063-11069, 2011.

VEGA-GÁLVEZ, A.; MIRANDA, M.; CLAVERÍA, R.; QUISPE, I.; VERGARA, J.; URIBE E.; PAEZ, H.; DI SCALA, K. Effect of air temperature on drying kinetics and quality characteristics of osmo-treated jumbo squid (Dosidicus gigas). LWT-Food Sc. Technol., v. 4(1), p. 16-23, 2011. 